Www.jmscr.igmpublication.org

Index Copernicus Value: 79.54

ISSN (e)-2347-176x ISSN (p) 2455-0450

crossref DOI: https://dx.doi.org/10.18535/jmscr/v7i6.134

Journal Of Medical Science And Clinical Research

IGM Publication

An Official Publication of IGM Publication

Original Article

\title{
Incidence and Management of Chemical Injuries of Eye
}

\author{
Authors \\ Dr Bishnu Prasad Mishra ${ }^{1}$, Dr Ankita Mahapatra ${ }^{2}$, Dr Santosh Kumar Sahu ${ }^{3 *}$, \\ Dr Choubarga Naik ${ }^{4}$, Dr Subha Soumya Dany ${ }^{5}$ \\ ${ }^{1}$ Ophthalmologist, District Headquarter Hospital, Balangir, Odisha. \\ ${ }^{2}$ Post-graduate student, Department of Ophthalmology, VIMSAR, Burla, Odisha \\ ${ }^{3}$ ENT Specialist, District Headquarter Hospital, Balangir, Odisha. \\ ${ }^{4}$ Assistant Professor, Department of Dentistry, VIMSAR, Burla, Odisha \\ ${ }^{5}$ Lecturer, Department of Public Health Dentistry, Hi-tech Dental College and Hospital, Bhubaneswar \\ *Corresponding Author \\ Dr Santosh Kumar Sahu \\ ENT Specialist, District Headquarter Hospital, Balangir, Odisha, India
}

\begin{abstract}
Introduction: Chemical injuries to the eyes are common and represent one of the true ophthalmic emergencies. Practically any chemical (acid or alkali) can cause ocular irritation.

Usually Acid burns are less severe than that caused by alkali burn.

Purpose: To study the incidence, pattern and management of chemical injuries of eye in a tertiary health care centre of Western Odisha

Method: A Hospital based study was undertaken in department of ophthalmology at between January 2017 to December 2018, which is a period of 2 years. A total of 102 patients were included in the study after counselling; and written informed consent was also taken individually in each case. Basic demographic data and history of chemical injury was noted. Treatment needed (according to degree and severity of injury) was provided to the patients at the Department of Ophthalmology. Patients were followed up for any complications for 6 months. Data obtained were subjected to descriptive statistics using SPSS 20.0.

Results: Out of all cases of ocular injuries; chemical injuries of eye were encountered in 13.04\%of cases during the study period. Males (73.5\%) were more affected and 31-40 years age group was the most vulnerable one. Most of the cases (59.8) presented with unilateral involvement of eye and 72 cases (70.59\%) of chemical injury were caused by alkalis. Grade II injury (35.6\%) was most common finding and some post-operative complications were also encountered during the follow-up.

Concussion: Chemical injuries to eyes maybe very few in number and minor in presentation but they also need early attention and care to minimize morbidity related to it.

Keywords: Acid, alkali, chemical injuries, complications, morbidity.
\end{abstract}

\section{Introduction}

Chemical injuries (alkali, acid) to the eyes represent one of the true ophthalmic emergencies which necessitate instantaneous and rigorous assessment and management. These represent between $11.5 \%-22.1 \%$ of ocular traumas ${ }^{1}$. About two thirds occur in young men and children age 12 years are particularly at risk. The vast majority 
of the injuries occur in the workplace as a result of industrial accidents. A minority of injuries occur in the home or secondary to assault. Practically any chemical can cause ocular irritation. Most of these injuries are inconsequential and do not cause serious lesions (e.g. shampoos, defence sprays, household cleaning solutions etc.) while other may result in permanent morbidity. Common acids are sulphuric acid (car batteries), hydrofluoric acid (glass polishing), acetic acid, hydrochloric acid and nitric acid (gold maker). Common alkalis are lime (plaster), ammonia/ammonium hydrochloride (cleaning solution, drain cleaner), potassium hydrochloride, magnesium hydrochloride (fireworks). Alkali injuries are usually more severe than acid injuries as the latter tends to remain confined to the ocular surface and producing superficial damage. ${ }^{2}$ When acid comes in contact with corneal surface they cause coagulation of tissue protein forming a barrier, which prevents deep penetration. But alkalis in contrast, cause saponification of cellular lipids disrupt the normal barrier of the cornea resulting in deep penetration to internal structures causing severe damage to the lens and anterior uvea. Alkali injuries tend to be more common since they are extensively used in industries and in various households as cleansing agent. Chemical trauma to the eye may vary in severity from mild irritation to complete destruction of the ocular surface epithelium, cornea opacification, loss in vision and rarely loss of the eye. ${ }^{3}$ The damage to the corneal and conjunctival epithelium from an ocular burn may be so severe as to damage the pluripotent limbal stem cell causing a limbal stem cell deficiency. This may lead to opacification and neo-vascularization of the cornea. An acute IOP rise occurrence due to shrinkage and contraction of the cornea and sclera is possible. Long-term IOP rises can occur from the accumulation of inflammatory debris within the trabecular meshwork, as well as due to damage to the trabecular meshwork itself. Damage to the conjunctiva can cause extensive scarring, perilimbal ischemia, and contracture of fornices.
Loss of goblet cells and conjunctival inflammation can leave the ocular surface prone to dryness. Lid malposition may be present due to symblepharon formation leading to cicatricial entropion or ectropion. ${ }^{4}$ In severe cases phthisis bulbi may be the tragic endresult. Chemical injury is the one of the true ophthalmic emergencies and it needs immediate management. Chemical burns have a major impact in terms of long-term morbidity and so is a matter of major socio-economic importance. The sequels of chemical burn may have significant detrimental visual and psychological effects on the affected individual. Proper management in the acute setting as well as follow-up by an ophthalmologist is crucial in limiting adverse effects of ocular tissue damage secondary to the chemicals. The aim of this study was to find out the pattern of ocular injury, nature of causative chemicals, the disabilities incurred and the outcome of treatment.

\section{Methods}

All the cases of chemical injuries attending to the Ophthalmologyout-patient department (OPD) and casualty of Bhima Bhoi Medical College and District Headquarter hospital, Bolangir, Odisha. during the study period from 01.01.2017 to 31.012.2018 were considered. A detailed clinical history of each case was taken with reference to name, age, sex, address and occupation. With particular reference to time since injury, place of injury and the chemical involved in each case made. Patient's chief complaint, personal history and past history were also noted. Prior to a full ophthalmic exam, the $\mathrm{pH}$ of both eyes checked, irrigated to bring the $\mathrm{pH}$ to an appropriate range (between 7 and 7.2). A thorough ocular examination (including normal eye) was done. The conditions of ocular adnexa, conjunctiva, cornea, sclera, anterior chamber, iris, pupil and lens were evaluated by slit- lamp examination and retained chemicals if any were removed. Distant visual acuity was recorded by Snellen's chart. Intraocular pressure was recorded, especially in alkaline burns. Fundoscopy was done by direct 
and indirect ophthalmoscope wherever possible. General examination and systemic examination, routine investigations were done in each case. All the patients were graded according to the severity of injury by Roper Hall (Modified Hughes) Grading of Ocular Chemical Injuries (Table 1). ${ }^{5,6}$ All the patients were treated by available therapeutic measures in best possible conservative way. Patients of grade 1 and grade 2 injuries were treated in the line of following conventional technique.

1. Immediate removal of chemical by thorough wash with normal saline and normalization of $\mathrm{Ph}$

2. Topical antibiotic ointment, drops

3. Preservative free artificial tear drops, Topical NSAIDs

4. Steroid to be used cautiously and Atropine $(1 \%)$

5. Systemic antibiotics, Doxycycline (to be avoided in children) anti-inflammatory agent and vitamin-C.

6. Conjunctival epithelium debridement from corneal surface

7. Acetazolamide, anti-glaucoma drops in cases of elevated IOP

8. Glass rod passed in the fornix in suspected cases of development of symblepharon

For G-III, IV non-healing injuries, following extra measures were taken, as per the suitability of the case

1. Bandage soft contact lens

2. Patching of the eye, tarsorrhaphy, Amniotic membrane graft

3. Systemic ascorbate

4. Tenonplasty

5. Autohemotherapy, subconjunctival injection of $0.5 \mathrm{cc}$ of the patient's own blood was given and repeated every alternate day as necessary

All the patients were followed up for a variable period of time extending from 1 week to 6 months, according to the grade of injury. In each follow up visit ocular condition was thoroughly examined and distant visual acuity was recorded. Long-term follow up for glaucoma, dry eye done.

\section{Result}

In this study 102 cases of chemical injury of eye were considered. They were of different age group and mostly were unilateral. Different varieties of injurious agents and mode of injuries were noted. All the injuries were classified according to Roper Hall grading and they were managed as aforementioned. The visual improvement in each and every case during the follow up period a maximum of 6 months was observed and compared with the initial visual acuity.

Table 2 shows out of 782 cases of ocular trauma 102 cases $(13.04 \%)$ of chemical injuries of eye were encountered during the study period. Out of total 102 cases of chemical injury, 75 cases $(73.5 \%)$ were found to be male and 27 cases $(26.5 \%)$ were female.

In this study the incidence of chemical injury in patients according to age group (Table 3) shows following trends: below 10 years was 4 (3.9\%) and between 11 to 20 years, it was 19 (18.6\%) and between 21 to 30 years 31 cases $(30.4 \%)$ were observed. 34 cases $(33.3 \%)$ were encountered in the age group of 31 to 40 years which was the highest so far and 9 cases (8.9\%) were in the age group of 41 to 50 years. In the group of 51 to 60 years of age, 5 cases $(4.9 \%)$ of chemical injuries of eye were found.

In total 143 eyes were involved in the 102 cases taken into account; out of which 61 cases $(59.8 \%)$ had unilateral and 41 cases (40.2\%) had bilateral involvement of eyes.

Table 5 shows the following observations:

1. Out of 26 eyes having the grade -1 injury, the pre-treatment VA was $6 / 6$ in 4 eyes $(15.3 \%)$ and $6 / 9$ in 22 eyes $(84.7 \%)$. After receiving treatment, the best corrected VA became $6 / 6$ in all 26 cases. The success rate in visual improvement was $100 \%$.

2. Out of 51 eyes having grade- 2 injury, the initial VA was $6 / 9$ in 18 eyes $(35.2 \%) 6 / 12$ or $6 / 18$ in 24 eyes $(47.05 \%)$ and in rest 9 eyes (17.6\%) VA was better than $6 / 60$ but worse than 6/18. The best corrected VA after treatment was $6 / 6$ in 44 eyes. Success rate 
was $86.2 \%$ Rest 7 eyes $(13.8 \%)$ improved to $6 / 9-6 / 12$.

3. Total No of eyes with grade-3 injury were 48 . Out of this, initial VA was better than $6 / 60$ but worse than $6 / 18$ in 14 eyes $(29.16 \%$ ), better than $1 / 60$ but worse than $6 / 60$ in 31 eyes(64.5\%) and HM only was present in 3 eyes $(6.25 \%)$.After treatment, the best corrected VA was improved to $6 / 18$ or better in 29 eyes (60.4\%). In 12 eyes (25\%) corrected VA improved to $6 / 60$ or better and in 7 eyes $(14.58 \%)$ best corrected VA improved to better than $1 / 60$.

4. Out of 18 eyes with grade -4 injury, the VA before treatment was $\mathrm{HM}$ in 12 eyes $(66.67 \%)$ and perception of light in 6 eyes $(33.33 \%)$. After treatment the best corrected VA was CF in 3 eyes (16.67\%) HM in 3 eyes (16.67) and PL in 9 eyes (50\%). In 3 eyes, there was perforation followed by infection which was finally eviscerated.

Table 1: Roper Hall (Modified Hughes) Grading of Ocular Chemical Injuries. ${ }^{5,6}$

\begin{tabular}{|l|l|c|c|}
\hline GRADE & CORNEA & LIMBAL ISCHEMIA & PROGNOSIS \\
\hline I & EPITHELIAL DAMAGE & NIL & EXCELLENT \\
\hline II & HAZE, IRIS DETAILS VISIBLE & $<1 / 3$ & GOOD \\
\hline III & $\begin{array}{l}\text { TOTAL LOSS OF EPITHELIUM, STROMAL } \\
\text { HAZE, IRIS DETAILS OBSCURED }\end{array}$ & $1 / 3-1 / 2$ & GUARDED \\
\hline IV & OPAQUE, IRIS AND PUPIL OBSCURED & $>1 / 2$ & POOR \\
\hline
\end{tabular}

Table 2: Incidence Of Chemical Injury In Relation To Total Number Of Ocular Trauma

\begin{tabular}{|l|c|c|}
\hline TOTAL NO OF OCULAR TRAUMA & TOTAL NO OF CHEMICAL INJURY & PERCENTAGE \\
\hline 782 & 102 & $13.04 \%$ \\
\hline
\end{tabular}

Table 3: Chemical Injury in different age group:

\begin{tabular}{|l|c|c|}
\hline AGE & NUMBER OF PATIENTS & PERCENTAGE \\
\hline $0-10$ & 4 & 3.9 \\
\hline $11-20$ & 19 & 18.6 \\
\hline $21-30$ & 31 & 30.4 \\
\hline $31-40$ & 34 & 33.3 \\
\hline $41-50$ & 9 & 8.9 \\
\hline $51-60$ & 5 & 4.9 \\
\hline
\end{tabular}

Table 4: Severity of chemical injuries:

\begin{tabular}{|l|c|c|}
\hline GRADE & NO OF EYES & PERCENTAGE \\
\hline I & 26 & 18.1 \\
\hline II & 51 & 35.6 \\
\hline III & 48 & 33.5 \\
\hline IV & 18 & 12.6 \\
\hline
\end{tabular}

Table 5: Visual outcome in relation to grades of injury

\begin{tabular}{|c|c|c|c|c|}
\hline $\begin{array}{l}\text { GRADE } \\
\text { INJURY }\end{array}$ & $\begin{array}{l}\text { TOTAL NO } \\
\text { OF EYES }\end{array}$ & VISUAL ACUITY & $\begin{array}{l}\text { NO. OF PRETREATMENT } \\
\text { EYES }(\%)\end{array}$ & $\begin{array}{c}\text { NO. OF POSTTREATMENT } \\
\text { EYES }(\%)\end{array}$ \\
\hline I & 26 & $\begin{array}{l}6 / 6 \\
6 / 9 \\
\end{array}$ & $\begin{array}{r}4(15.3) \\
22(84.7)\end{array}$ & $\begin{array}{c}26(100) \\
-\end{array}$ \\
\hline II & 51 & $\begin{array}{c}6 / 6 \\
6 / 9 \\
6 / 12 \text { or } 6 / 18 \\
>6 / 60 \text { and }<6 / 18\end{array}$ & $\begin{array}{c}-- \\
18(35.2) \\
24(47.05) \\
9(17.6)\end{array}$ & $\begin{array}{c}44(86.2) \\
7(13.8)\end{array}$ \\
\hline III & 48 & $\begin{array}{c}6 / 18 \text { or BETTER } \\
>6 / 60 \text { and }<6 / 18 \\
>1 / 60 \text { and }<6 / 60 \\
\text { HM }\end{array}$ & $\begin{array}{c}-- \\
14(29.16) \\
31(64.5) \\
3(6.25)\end{array}$ & $\begin{array}{c}29(60.4) \\
12(25) \\
7(14.58) \\
--\end{array}$ \\
\hline IV & 18 & $\begin{array}{l}\text { CF } \\
\text { HM } \\
\text { PL }\end{array}$ & $\begin{array}{c}-- \\
12(66.67) \\
6(33.3)\end{array}$ & $\begin{array}{c}3(16.67) \\
3(16.67) \\
9(50)\end{array}$ \\
\hline
\end{tabular}


Table 6: Complications

\begin{tabular}{|l|c|c|}
\hline COMPLICATIONS & NO OF CASES & PERCENTAGE \\
\hline CORNEAL SCARRING & 54 & 37.76 \\
\hline DRY EYE & 46 & 32.16 \\
\hline LID DIFORMITY & 23 & 16 \\
\hline SYMBLEPHARON & 9 & 6.29 \\
\hline GLAUCOMA & 42 & 29.3 \\
\hline CATARACT & 16 & 11.1 \\
\hline PERFORATION & 3 & 2.09 \\
\hline
\end{tabular}

\section{Discussion}

The present study was conducted in the Dept. of Ophthalmology, between $1^{\text {st }}$ January 2017 to $31^{\text {st }}$ December 2019.Out of the total 782 cases of ocular trauma attending the OPD and casualty, 102 cases of chemical injury of the eye were accounted. All the cases were studied in detail and they were graded according to Modified Hughes grading system. The best possible and available conservative methods of treatments was given to every case depending upon the severity of injury. All the cases were followed up for a maximum period of 6 months.

The incidence of chemical injury in relation to the total number of ocular traumas during the study period was $13.04 \%$.The incidence of chemical injury; reported by Verson SA et $\mathrm{al}^{7}$ (1983) was $7 \%$ to the total number of ocular trauma. Study by Jones N.P et $\mathrm{al}^{8}$ (1986), reported the incidence of $9.9 \%$ of all ocular trauma. But Karaman et $\mathrm{al}^{9}$ (2004) and Ho.C.K.Yen et $\mathrm{al}^{10}$ (2007) reported the incidence of $13.6 \%$ and $19.6 \%$ of all ocular trauma respectively. Chemical injury cases increase due to vast use of chemicals in many fields, industries and day to day works. In the present study, the incidence of chemical injury was $11.2 \%$ of all ocular trauma, which seems to be higher in comparison to the 1983 and 1986 studies, similar to 2004 but less than 2007 study.

Higher incidence of chemical injury was found in male $(73.5 \%)$ than female (26.5\%).Marijamatovic et al ${ }^{11}$ (2014) found that males were more often reported with injures than females $(66.37 \%$ vs. $33.63 \%)$. Subrat das et al $^{12}$ (2015) found that male to female ratio was $1.7: 1$. Preponderance of male to chemical injury is more because of their more exposure to industrial works, agricultural fields and other outdoor activities
The lowest incidence of $3.9 \%$ was encountered in the age group below 10 years. Higher percentage of chemical injury was observed in the age group of 31 to 40 years $(33.3 \%)$ and 21 to 30 years $(30.4 \%)$.This is due to the fact that, people of this age group are the main working member of the society. P.Singh et $\mathrm{al}^{4}$ (2013) also studied and found that the chemical injury patients are mostly found in age group between 20 to $40 \mathrm{yrs}$. Aleksandra Radosavljevic et $\mathrm{al}^{13}$ (2013) also reported that in between 21-40years ocular chemical injury constituted of $48.5 \%$.

In our study, 72 cases (70.59\%) of chemical injury were caused by alkalis and 19 cases $(18.6 \%)$ by acids and rest 11 cases (10.8\%) were caused by other agents. Aleksandra Radosavljevic et $\mathrm{al}^{13}$ (2013) found in his study that $73 \%$ were affected by alkali chemical injury and only $18.2 \%$ affected by acids, which is simillar.

Out of 102 cases, unilateral involvement of either right or left eye was found in 61 cases $(59.8 \%)$ whereas bilateral involvement was in 41 cases (40.2\%). Aleksandra Radosavljevic et $\mathrm{al}^{13}$ (2013) reported in his study that unilateral cases are more that of $63.5 \%$ than the bilateral of $36.5 \%$.

Out of 143 eyes of 102 cases, 26 cases (18.1\%) were of grade- 1 and 51 cases $(35.6 \%)$ were in grade -2 injury. Grade -3 injury was found in 48 cases $(33.5 \%)$ and grade -4 injury in 18 cases (12.60\%). Aleksandra Radosavljevic et al ${ }^{13}$ (2013) found in his study and concluded that Grade-1 chemical injury constituted of only 4, Grade-2 of $31.1 \%$, Grade-3 of $42.6 \%$ and Grade- 4 of $18.3 \%$ (in $4 \%$ no data available). It is concluded that Grade-2 and Grade-3 ocular chemical injuries constituted most cases. (Table 4)

Nimmymerin Mathew et $\mathrm{al}^{14}$ (2017) in a study found among the 34eyes with chemical injury on 
review after 2 months, 30 eyes had best corrected visual acuity improved to $6 / 6-6 / 18(88.2 \%)$. Still, 3 eyes $(8.8 \%)$ had their visual acuity in the range of $6 / 24-3 / 60$ and one eye had visual acuity $<3 / 60$. During the course of treatment and follow up period, several cases were found to have some complication (Table 6). In 54 eyes $(37.76 \%)$ there was corneal scarring. Dry eyes were found in 46 eyes $(32.16 \%)$, most of which were due to either severe scarring of cornea or due to lid deformity. The lid deformity of various types was found in 23 eyes (16\%). Symblepharon was seen in 9 eyes (6.29\%). Glaucoma developed in 42 (29.3\%) eyes. Cataract as a complication of chemical injury was found in 16 eyes $(11.1 \%)$. In those eyes having severe corneal scar, the detection of cataract was not possible. In 3 eyes $(2.09 \%)$ there was perforation followed by infection which was finally subjected to evisceration.

\section{Conclusion}

Chemical injuries of the eye, though constitutes a small fraction of ocular trauma, but it needs early attention to minimize complications.It can be concluded that the majority of cases of chemical injury of eye are likely to be minor and in those, where significant injury has occurred, early and intensive management may secure a good prognosis and minimize long term sequelae.

\section{References}

1. Clare, G., et al., Amniotic membrane transplantation for acute ocular burns. Cochrane database of systematic reviews, 2012. 9: p. CD009379.

2. Burns FR, Paterson CA. Prompt irrigation of chemical injuries may avert severe damage. Occup Hlth 1985; 58: 33-36

3. Pfister RR. Chemical Injuries to the eye. Ophthalmology 1983; 90:1246- 1253

4. Singh P, Tyagi M, Kumar Y, Gupta KK, Sharma PD. Ocular chemical injuries and their management. Oman J Ophthalmol. 2013;6(2):83-86. doi:10.4103/0974620X.116624
5. Hughes, W., Alkali burns of the eye. I. Review of the literature and summary of present knowledge. Archives of ophthalmology, 1946. 35: p. 423.

6. Roper-Hall, M.J., Thermal and chemical burns. Transactions of the ophthalmological societies of the United Kingdom, 1965. 85: p. 631-53.

7. Verson SA; Analysis of all new cases seen in a busy regional center ophthalmic casualty department during a 24 week period. J.R .Soc. Med, 1983; 76:273-282.

8. Jones NP, Hayward JM, Khaw PT, Claoue CNP, Elkington AR; Function of an ophthalmic accident and emergency department; result of a six month survey; Br. Med. J. 1986; 292:188-190

9. Karaman K, Gvoreovic .AntinicaA, Rogosia V, Lokos-KazetjV, RozgaA, S: Epidemiology of adult eye injuries in Split-Dalmatia country,Croatia Med J 2004;304-309.

10. Ho.C.K.Yen, Y.K.Chang, H.C.Shen, Y.Y.Chang, P.Y: Epidemiologic study on work related eye injury in Kaohsiung, Taiwan, Kaohsiung J Med 2007 Sci23:463-469.

11. Marija Matovic, Katarina Janicijevic, Mirjana A. Janicijevic Petrovic PONS Med Č 2015 / PONS Med J 2015; 12(2):64-67 [10].

12. Subrata Das, Md. Firoz Kabir, Joyabrata Das, Ahmed Abdul Hannan, Md. Wazed Chowdhury, Saiem Mohd Nurul Anwar, Rajiv Mothey Chattagram Maa-O-Shishu Hospital Medical College Journal Volume 13, Issue 1, January 2014

13. Aleksandra Radosavljevic, Tanja Kalezic, Slobodon Golubovic, SrpArhCelok Lek,2013 Sept-Oct; 141:592-596.

14. Nimmy Merin Mathew, Mallika. O.U. JMSCRVol|| 05|| Issue || 03|| Page 1937919383|| March 2017. 